\title{
Study of Status Quo and Countermeasures of Foreign College Students ' Mental health
}

\author{
Qi Fu \\ Guangxi University of Finance and Economics, Nanning Guangxi, 530003, China
}

Keywords: College students, Mental health education, Mode

\begin{abstract}
This paper analyzes the Status quo, specific educational mode and characteristics of students' mental health education in the foreign universities, and to learn advanced mental health education from foreign, to inspire the mental health education for college students in china
\end{abstract}

\section{The present situation of mental health education for College Students}

\section{Value orientation is developing and active.}

Mental health education is a special kind of social service, in Psychological education for College Students, first we should have enough respect and attention for Psychological needs of College Students, care for their spiritual life, pay attention to the position of the person, promote the full development of people, pay attention to their lives and life. The traditional Mental health education of foreign students is only limited to the correction, the object of the service is the students who have psychological problems or the difficulties, But these students are only a minority, the majority of normal students did not provide any help.

Although in college students' mental health education, the correction work is very important and indispensable, but it is more emphasized that adopt explore the psychological potential of students to improve their mental health level. Today's developed countries such as Europe and the United States and Japan have set up a mental health service organization in the university, prevented college Students' psychological disease and achieved good results, The focus of the consultation is no longer an obstacle consultation, but has become the main direction of development. At the same time, the other changes are value orientation, the object of mental health education, the ultimate goal, covering a wider area and more targeted.

\section{Service scope is more extensive.}

The form, content and scope of health education has large difference. Such as Africa, Asia, the services provided by the developing countries are relatively single, The American college students mental health education is more diverse and comprehensive, such as to guide students to carry out the choice of occupation and study, to consult the social problems and emotional problems of students, and to provide advice for parents and teachers to provide advice to parents and teachers, It also includes the development of the service organization itself, such as the professional research on the organization development. For services provided by the United States, the psychologist Thomas has classify into direct intervention, indirect intervention, individual assessment, research assessment, supervision and management and prevention. Japan's psychological counseling services for college students include the four aspects Advisory: Life, learning development, psychology and mental health. French Ministry of education has plan the three development direction, respectively is the trend, the integration and the intervention. In foreign countries Teachers of mental health education of college students are the main role to play the following six: To protect students' mental health, to guide students' learning life, to guide students to carry out their professional choice, to guide students' Ideological and moral development, to excavate the psychological potential of students, and to promote their psychological development. 


\section{Mental health education model of foreign college students}

\section{Correction mode.}

Correction mode is the obstacle of the model, The object of this model is who have mental illness or mental disorder, The relationship between workers and service objects is similar to the relationship between doctors and patients, To carry out different levels of psychological treatment or counseling based on the symptoms of the service object. The stage of the model is as follows: The first is to communicate with patients, to understand the patient's specific situation; second is to specific analyze the situation, identify the specific symptoms and psychological diagnosis model; the third is to eliminate students' psychological barriers through the treatment, the characteristics of this model is clinical. However, this model whether the consultation or the data should be proceed with caution, to ensure the treatment is active acceptance of the treatment, this education strategy is a remedy in the psychological disorder, the passive behavior, only for a few people, but is the most in the world of education mode, also the most basic mental health education measures.

\section{Development model.}

Development mode is mainly to prevent the generation of mental illness, to ensure the full development of people, this model is primarily a service to the normal growth of the students, to help them to remove obstacles such as learning, interpersonal relations and employment and other aspects of the pressure, and thus more healthy life.

\section{Psychological counseling model.}

The psychological counseling model include three forms: Invitation, psychological counseling, and Consultant teacher program, American colleges and universities generally used these models. Invitation mode is first proposed in 1987, Based on the theory of "invite" education, it emphasizes that the process of education should give full respect to each individual's potential and value, and active use the resources such as personnel, material, education plan, education policy and so on. To enhance the attractiveness of the school, so that students in the school feel valued, welcome and appreciation, the student is more willing to accept this model. The psychological counseling model and Consultant teacher program have a same characteristic that more valuing the development of psychological counseling and comprehensive, combining the psychological counseling with teaching, in the psychological counseling give full play to the positive role of teachers, to help students achieve the common development of all aspects of ability. Overall development model, psychological counseling, and Consultant teacher program is different in approach but equally satisfactory in result.

\section{Taking visitor as center mode.}

The taking Visitor as center mode, which was founded by Rodgers (American psychologist), is called a non-directive therapy. The center of this model is the visitor in the process of psychotherapy. This model has the following three characteristics: the first is to have absolute confidence in the visitors, believe they can through their own efforts and the counselors treatment, slowly change their own; the second is between counseling staff and visitors to establish a good relationship, so to successfully communicate with visitors, the counseling staff will be sincere and cordial, visitors are not hostile to the staff, the two sides can become the friend and have enough sense of security and rely on; the three is the consultant should weaken the guidance, do not need to have awareness of the diagnosis, treatment and guidance, but listen to the visitors, let visitors released their potential and their own distortions self-change, realize the "inaction".

\section{The characteristics of foreign students' Psychological Education}

The Agency regularization and the personnel specialization.

The mental health education of college students began in some developed countries. At the beginning of twentieth Century, the United States has begun the education of College Students' mental health, and in Japan has carried out the education of College Students' mental health in the middle of twentieth Century. In these countries, there are generally a professional college students' mental health education institutions, and the relevant psychological health and counseling agencies. Universities in Europe and the United States will generally set up a institution of mental health 
education, usually there will be a certain number of full-time staff, generally about 10 people. But in addition to professional counselors and professional counseling staff, schools will established psychological consulting organization with student' s workers. In japan, the school will also allocate special funds to maintain the normal operation of the organization. In addition, there is a part of the university will also take mental health education institutions as one of the specialized departments of the school.

In foreign countries, the requirements of mental health education practitioners are very high, so that they can guarantee the professional of the staff. In the United States, most of the schools require the mental health education staff must receive a doctoral degree, and through the corresponding qualification examination, so that they can have the qualification of independent complete psychotherapy. Therefore, most schools have set up special psychological counseling, school psychological education and other related professional, developed more professional psychological counseling staff. Similarly, in Europe, the state stipulate psychological counseling staff must have a graduate degree or above, also have teacher qualification certificate, in addition, it should have the appropriate educational psychological work experience, and on-the-job staff, must be involved in the training, after training, only through professional counseling and assessment then can get a formal psychological counseling practitioners.

\section{The diversification of Content and form.}

Generally, in the initial stage of the psychological counseling industry, the attitude of the European and American countries for mental health education is only to be corrected, and counseling is just for some people to carry out. After that, because of the continuous emergence of various social problems, as well as the further development of the psychological counseling industry, people also will increase the understanding of psychological counseling. As a result, the object of psychological counseling is gradually transferred to the majority of normal students, and the focus of psychological counseling is also from the obstacle to the development of counseling, at the same time, along with the transformation of College Students' ideas and values, the mental health education of college students also has changed in content and form..

Generally speaking, the foreign students' psychological health education work includes four aspects of content, the first is Expand the work of psychological education for the students with mental illness, these students may due to personal reasons or social problems are caused the depression or extreme. The second is to carry on daily psychological guidance to the student in love, social, family and religion and other aspects; The third is to make the relevant guidance to students about study and employment selection, usually including the method of learning, the choice of employment, the future development of the road and some other issues; the Fourth is to make Mental health counseling to Prevent the mental disease of students.. Therefore, the characteristics of the mental health education of foreign students is obvious, that is to ensure the health of the psychological, to guide the daily life, to guide the future career and to guide the correct values.

In foreign countries, mental health education generally has a wide path and a variety of forms. From a macro perspective, in addition to mental health education to students, mainly including the penetration in students living and the establishment of a healthy library, etc., the college should also have the unique psychological education aid. And from the microscopic, in order to help the healthy growth of college students, the school will generally from the environment, parents, individuals, groups in these aspects make psychological intervention, so as to better help college students to solve the psychological problems, and to correct and prevent.

\section{Resources Comprehensive and Mode localization.}

Usually the psychological problems of college students in developed country is more serious, this is the inevitable result of social development. These psychological problems mainly include excessive drinking, violence, suicide and sexual crimes, therefore, only rely on psychological counseling and counseling work has been far from able to solve the psychological problems of College students. So, since 1980s, most schools have started the reform of mental health education, through the reform of education mode and integrating resources, so realize the integration of educational psychological resources. In addition, due to the differences of the country's basic national 
conditions, in order to achieve the goal of psychological health education to university students, we must according to the specific circumstances of the local carry out college students mental health education, for example, should take education assistance in poor areas, and should take Students' learning guidance in areas with high dropout rates. The expansion of this series of work has shown the local characteristics of the psychological health education.

\section{Inspire to our country by foreign students' mental health education}

To ensure that educational measures are more targeted and effective. Our country can learn from foreign experience, the basic knowledge of psychological health will be from many ways to spread, to carry out discipline penetration by the creation of professional courses, to ensure the diversity of psychological counseling and to establish a special college students' psychological files, normal mental health education work is prevention. At the same time, some of the practices of foreign countries are very humane and full of personality, such as parents and environmental intervention, Harvard University, and arrange the mental health teachers in student apartments, these can inspire our work.

Although our country has carried out the mental health education of university students, but there are still a lot of maturity, the number of professional scholars still have a big problem, and especially the education administrative department and the society is not enough to pay attention to it. Therefore, we must have a more profound understanding of mental health education, from the aspects of human and investment to provide protection; the second is to let the family, teachers, social and so on to played positive role, and to form a new situation

\section{References}

[1] Lv Wei, Du Juan, Wang Zhenhong, etc. The relationship between College Students' positive emotions and mental health: the mediating effect of personal resources. Chinese Journal of mental health, 2011, 25(7):521-527.

[2] Liu Zhimin, Xu Na. A study on the relationship between body image and mental health of students with disabilities. Special education in China, 2013, (11):36-42.

[3] Li Ling, Li Qiang. Feasibility study of promoting the development of College Students' mental health services with the concept of social marketing. Chinese Journal of mental health, 2014, 28(12):886-890.

[4] Lu Qin, Zheng Hanyu. The effect of mental health curriculum and its influence on College Students' sense of life. Chinese Journal of health psychology, 2014, (9):1395-1397, 1398.

[5] Hu Kai, Jiang Qiaoling. Research progress and tendency of College Students' network mental health education. Modern university education, 2011, (6):81-86,111. 